\title{
Korrespondenzen.
}

\section{Ueber Fremdkörper im Uterus als Mittel zur Verhütung} der Konzeption.

Erwiderung auf die Mitteilung von Dr. Liek (Danzig).

Von Dr. Richter in Waldenburg (Schl.).

Nr. 19 dieser Wochenschrift, die verspätet zu meiner Kenntnis gelangt ist, enthält eine Beobachtung des genannten Kollegen, derzufolge in den Uterus eingelegte Silkwormfäden auf dem Wege einer Endometritis zu einer schweren eitrigen Adnexerkrankung geführt haben sollen, die operativ beseitigt werden mußte. Zur Herstellung des ursächlichen Zusammenhangs zwischen dem Anticoncipiens und der Erkrankung der Adnexe geht Liek von der Voraussetzung aus, daß wie in seinem so in allen anderen Fällen die Silkfäden eine Endometritis erzeugen müssen. Nach meinen Beobachtungen und denen anderer Aerzte, die mir ihre Erfahrungen mitgeteilt haben, ist dies nicht zutreffend. In der Mehrzahl der Fälle werden die Fäden anstandslos, ohne Schmerzen, ohne menstruelle Störungen vertragen. Es hat sich ferner tatsächlich gezeigt, daß nach Entfernung der Fäden der Uterus alsbald wieder konzeptionsfähig geworden ist. In dem Liekschen Falle sind einige Monate nach Einführung endometrische Erscheinungen, in Form schmerzhafter und verstärkter Menses, aufgetreten. Da Liek die Fäden nicht selbst eingelegt hat, wird er nicht wissen können, in welcher Weise dies geschehen und ob der Uterus aufnahmefähig gewesen ist. Die Einführung ist, wie ich in meiner ersten Mitteilung (No. 39, Jahrgang 1909 dieser Wochenschrift) betont habe, nicht immer ganz leicht. Sie muB schonend, unter aseptischen Kautelen und, ohne Verletzungen zu setzen, erfolgen. Daß es ferner Frauen, auch mit gesunden Organen, gibt, die aus nicht erkennbaren Gründen das Mittel nicht vertragen, habe ich bereits früher hervorgehoben. Diese Beschränkung teilt das Mittel wohl mit jedem anderen in der Therapie verwandten. Derartige Fälle sind aber nicht häufig.

Antikonzeptionelle Mittel sind nicht zu entbehren für den Arzt, der mit der leidenden Frauenwelt in Berührung kommt. Solange es daher kein besseres und dezenteres Mittel als das von mir angegebene gibt, das jede mißbräuchliche Verwendung ausschließt, wird es in geeigneten Fällen weiter benutzt werden dürfen. 